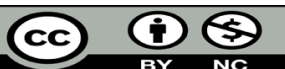

Licenciado sob uma licença Creative Commons

ISSN 2175-6058

DOI: https://doi.org/10.18759/rdgf.v19i1.942

\title{
JURISDIÇÃO CRIMINAL BRASILEIRA E AS CORTES INTERNACIONAIS DE DIREITOS HUMANOS: DIÁLOGOS NECESSÁRIOS
}

\author{
BRAZILIAN CRIMINAL JURISDICTION AND INTERNATIONAL \\ HUMAN RIGHTS COURTS: NECESSARY DIALOGUES
}

\author{
Denise Luz \\ Nereu José Giacomolli
}

\section{RESUMO}

O diálogo necessário entre as Cortes, no plano vertical e também horizontal permite o estabelecimento de standard protetivo das garantias processuais criminais, inseridas no âmbito do justo processo penal. A transposição da normatividade e da jurisdicionalidade domésticas, na perspectiva da superação do monólogo doméstico, são exigências de uma tutela jurisdicional efetiva. A efetividade das garantias processuais penais exige aderência legal, constitucional e, sobretudo, convencional pro homine.

Palavras-chave: Jurisdição criminal. Diálogos verticais e horizontais. Justo processo.

\section{ABSTRACT}

The necessary dialogue between Courts - in the vertical and horizontal axis - also allows the establishment of protective standard of criminal procedural guarantees, inserted under the criminal due process of law. The implementation of domestic regulations and jurisdiction in view of overcoming the domestic monologue, are requirements for an effective judicial protection. The 
effectiveness of criminal procedural guarantee requires legal, constitutional and, above all, conventional adherence under the pro homine principle.

KEY WORDS: Criminal jurisdiction. Vertical and Horizontal Dialogues. Fair Trial.

\section{INTRODUÇÃo}

Insofismável a inserção do Brasil no Sistema Interamericano de Direitos Humanos, a partir do Pacto de São José da Costa Rica, sobretudo em razão da interpretação que lhe é dada pela Corte Interamericana de Direitos Humanos (Corte IDH) em matéria de garantias processuais penais. A partir da normatividade (Convenção Americana de Direitos Humanos- $\mathrm{CADH}$ ) e da jurisdicionalidade (decisões da Corte Interamericana e opiniões consultivas) internacionais é possível estabelecer um standard mínimo de proteção conferida a toda pessoa, sempre que submetida à intervenção punitiva de agências estatais. 0 desenho desse standard mínimo, em nível nacional, resulta do diálogo horizontal e vertical entre cortes ou diálogos jurisprudenciais que alimentam e empoderam o sistema interno de proteção dos direitos humanos, ofertando efetividade ao devido processo penal e a seus elementos estruturantes. Esse estudo impacta juridicamente, na medida em que o diálogo da jurisdição brasileira com as cortes internacionais de direitos humanos ainda se mostra tímido, carecendo de maior problematização, aprofundamento, compreensão e efetividade. Ademais, carente a doutrina brasileira da abordagem internormativa e interjurisdicional. 0 problema que se apresenta é se a normatividade e a jurisdicionalidade domésticas são suficientes à tutela efetiva das garantias processuais penais, ou seja, do justo processo.

A inserção da normatividade internacional à problemática interna de efetividade na proteção das garantais processuais penais carece, no plano brasileiro, de uma ampla abordagem e de um constante labor, de modo a possibilitar uma base teórica que dê sustentação à convencionalidade, ao diálogo entre as cortes, bem como à inserção das normas internacionais de proteção dos direitos humanos, no denominado "bloco de constitucionalidade". Sustenta-se, essa perspectiva, no necessário diálogo entre 
as cortes, na normatividade e interjurisdicionalidade contemporâneas, inseridas no contexto do complexo diálogo entre as cortes.

Num primeiro momento, o estudo aborda a inserção das garantias processuais na perspectiva dos direitos humanos, em face dos diplomas internacionais ratificados pelo Brasil, do Tribunal Europeu de Direitos Humanos (TEDH) e da Corte IDH. Em um segundo momento, o artigo trata da comunicação das decisões entre tribunais (diálogo jurisdicional das fontes). Por fim, se defende a superação do monólogo jurisdicional brasileiro, na perspectiva do diálogo entre as cortes, na perspectiva horizontal e vertical.

\section{GARANTIAS PROCESSUAIS PENAIS E DIREITOS HUMANOS}

Das declarações e convenções de direitos humanos se inferem garantias processuais penais, entendidas como um mínimo de exigência de proteção, ademais de irrenunciáveis, presentes em qualquer estado democrático. Os principais documentos jurídicos internacionais sobre direitos humanos estipulam garantias processuais: CADH (1969), Convenção Europeia de Direitos Humanos - CEDH (1950), Declaração Universal dos Direitos Humanos - DUDH (1948), Pacto Internacional de Direitos Civis e Políticos - PIDCP (1966), Carta Africana de Direitos dos Homens e dos Povos (1981), e Carta de Direitos Fundamentais da União Europeia.

Segundo Diego Garcia-Sayán (ORGANIZAÇÃO DOS ESTADOS AMERICANOS, 2012), Juiz da Corte IDH, as garantias processuais têm sido de fundamental importância na jurisprudência daquela Corte porque a experiência tem demonstrado que elas afetam de maneira ampla e profunda os direitos das pessoas. Afirmou que "o tema do devido processo tem sido e segue sendo de presença permanente nos casos apresentados à Corte Interamericana". Até outubro de 2011, em mais de 95\% dos casos decididos pela Corte IDH reconheceu-se violação de garantias processuais previstas no artigo $8^{\circ}$ da CADH. ${ }^{1}$

Desde o reconhecimento da competência da Corte IDH, em 1998, o Brasil respondeu a nove processos contenciosos: Caso Herzog (2018), Caso Favela Nova Brasília (2017), Caso do Povo Indígena Xucuru (2018), 
Caso Gomes Lund e Outros ou "Guerrilha do Araguaia" (2010), Caso Escher e Outros (2009), Caso Garibaldi (2009), Caso Nogueira de Carvalho (2006) e outro, Caso Damião Ximenes Lopes (2006), e Caso Trabalhadores da Fazenda Brasil Verde (2016). Em todos foram discutidas supostas violações de garantias judiciais (art. 8o) e de proteção judicial (art. 25). Exceto no Caso Nogueira de Carvalho e outro, no qual a Corte julgou não ter restado provada a violação de tais artigos, em todos os outros, foi reconhecida a responsabilidade internacional do Brasil por violação de garantias processuais (art. 8o e 25).

Até o ano de 2012, a violação do artigo 60 do CEDH perfazia 31,17\% das declarações do TEDH e a violação do art. 13 - acesso à justiça - correspondia a 8,25\%. Pelo que se observa, o índice de violação das garantias processuais atingiu 38,42\% das declarações do TEDH naquele ano. No ano de 2013 , o percentual foi de $38,88 \%$. Em 2014, houve uma pequena queda para $35,31 \%$ e, em 2015, para 33,59\%. Até o fechamento deste artigo, o percentual apurado para o ano de 2016 estava em 32,60\%, segundo dados provisórios do próprio TEDH (COUNCIL OF EUROPE, 2013, p. 153, 2014, p. 195, 2015, p. 164, 2016, 191, 2017, p. 197).

Isso permite reconhecer que as garantias processuais integram o elenco dos direitos humanos, mormente as que dizem ao justo processo. Logo são "emanações da dignidade humana o que explica sua essencialidade ou 'prioridade axiológica' a impor sua proteção por sua importância intrínseca ligada não só à pessoa humana individualmente considerada". (SALDANHA, 2010a, p.128). o justo processo pode ser compreendido como "um processo capaz de viabilizar concretamente o mínimo de garantias que se pode esperar e exigir de um sistema jurídico democrático" (LUZ, 2014). Esse mínimo de garantias - ou garantias mínimas - encontra espeque na historicidade dos direitos humanos, naquilo em que há consenso entre os povos como sendo parte irrenunciável do espaço de liberdades individuais conquistadas.

Segundo Saldanha (2010b, p. 686), o processo é "uma instituição constitucional garantidora dos direitos fundamentais", ademais de uma instituição convencional, também garantidora dos direitos humanos e de uma solução justa para o caso submetido ao crivo jurisdicional. 0 direito ao justo processo é um direito humano e as garantias processuais, por 
si, merecem proteção internacional, independente do direito material involucrado. Toda pessoa possui direito ao justo processo pelo simples fato de ser pessoa, independente de ser considerada formalmente cidadão do país. Isso se reveste de grande relevância porque é na dinâmica do processo que os Estados podem, efetivamente, atuar de modo arbitrário ou em harmonia com os direitos humanos.

Na dinâmica do processo é que o Estado interfere diretamente na liberdade dos indivíduos. É no campo do direito processual que se dá a intervenção repressora estatal, sendo ele a primeira "instituição constitucional/convencional" a sofrer restrições durante os regimes de exceção, como ocorreu com a eliminação do Habeas Corpus durante o regime militar brasileiro. ${ }^{2}$ Foi exatamente a garantia do estado de inocência que foi afastada, ou pelo menos, significativamente limitada em alguns países, após os atentados terroristas de 11 de setembro, o que justificou até o afastamento das Miranda Rules ${ }^{3}$ aos suspeitos. Isso sem mencionar a manutenção de prisioneiros em Guantánamo, durante anos, sem acusação formal contra eles, impedindo o exercício da defesa. É pela necessidade de proteger as pessoas contra a violência institucionalizada que os pactos internacionais de direitos humanos destinam proteção às garantias processuais de defesa, reconhecendo o direito ao justo processo, como um direito humano. Os direitos humanos surgiram como reação à arbitrariedade e brutalidade consumada pelos Estados, por intermédio de todos os poderes, não apenas do Executivo.

\section{PERSPECTIVAS NO TEDH}

A doutrina do justo processo foi desenvolvida no âmbito do TEDH que, chamado a decidir sobre o respeito às garantias processuais mínimas em sistemas jurídicos tão distintos - de common Law e civil Law, logrou êxito na harmonização, frente aos dispositivos do CEDH. O fato de o TEDH só conhecer casos que possam, em abstrato, ser enquadrados em alguma das violações do CEDH, leva a sua doutrina a propiciar a elaboração de um "denominador comum" sobre as configurações do justo processo, 
independente das diferenças entre os sistemas jurídicos (ARMENTA DEU, 2012, p. 275).

Segundo Armenta Deu (2012, p. 275), o justo processo não necessariamente vincula-se aos modelos adversarial, misto ou acusatório de processo penal. Não há registros de que o TEDH (ou a Corte IDH) tenha se preocupado em classificar os sistemas processuais de cada país para definir qual seria o melhor. Ao contrário, superando a dicotomia entre os sistemas processuais acusatório-inquisitório ou mixto-adversarial, o TEDH vem desenvolvendo um quadro de direitos processuais comuns $e$ irrenunciáveis (ARMENTA DEU, 2012, p. 275). Nessa linha, o que interessa não é a classificação de um sistema processual, mas a elisão de práticas estatais que minam o exercício das garantias processuais e o fortalecimento da capacidade de ambos os sistemas de concretizar as garantias previstas nos respectivos diplomas internacionais. 0 justo processo harmoniza os diferentes sistemas processuais em relação ao CEDH, mas não consiste em um terceiro modelo. Essas garantias mínimas que conformam o justo processo contam com parâmetros objetivos de identificação e medida do âmbito de alcance definidos em tratados internacionais (LUZ, 2014). 0 TEDH considera que a aplicação ou negação das garantias do artigo 6ํㅜ da CEDH, e também do 7º, quando exigíveis, é que definem a observância ou não do justo processo. Um processo que não viabiliza concretamente o exercício dessas mínimas garantias não pode ser considerado um justo processo - fair trial, logo é um unfair trial (COUNCIL OF EUROPE, 2012).

O TEDH reconhece a independência dos Estados na definição dos regimes jurídicos aplicáveis aos ilícitos estipulados na legislação doméstica como penal, civil ou administrativo, não podendo a Corte Europeia adentrar no mérito dessas escolhas, desde que sejam respeitadas as garantias mínimas previstas no artigo 6음 do Convênio Europeu de Direitos Humanos - Right to a fair trial. Isso significa que mesmo que um ilícito não seja tratado como de natureza penal pelo Estado, sendo punido como ilícito administrativo ou civil, o Estado não pode se escudar nesse argumento dogmático para, simplesmente, negar ao acusado as garantias previstas no CEDH. O TEDH afirma que se os Estados pudessem livremente escolher o regime jurídico a ser aplicado ao ilícito com o intuito de elidir a regra do artigo 6º do Convênio Europeu - já que este especifica que os direitos 
e garantias nele previstos são aplicáveis ao processo penal - a Convenção se tornaria ineficaz para proteger direitos humanos, bastando ao Estado alterar a classificação formal do ilícito baseado em critérios de política repressiva e eficiência. Por isso, independente da classificação do ilícito no ordenamento jurídico interno, o TEDH considera a natureza do ilícito, a severidade da pena e outras características para impor as garantias do processo penal a todo processo sancionador (LUZ, 2014).

Nota-se que o TEDH, ao invocar a natureza do ilícito, não se apega em razões transcendentais ao gosto metafísico, mas adota critérios de interpretação histórica das normas, de direito comparado e de diálogos jurisprudenciais, sempre se voltando para a funcionalidade garantista do processo. A historicidade dos direitos humanos e critérios de cross-fertilization permitem ao TEDH verificar como o ilícito foi tratado nos diferentes países ao longo da sua evolução democrática, bem como firmar critérios ao julgamento de ilícitos idênticos ou semelhantes, com o fito de atingir um maior espectro de absorção e aceitação universal. Esse entendimento foi, pioneiramente, adotado no Case of Engel and Others vs. The Netherlands (LUZ, 2014).

o justo processo abarca o estado de inocência como fundamento. A eficácia das garantias e a concretização do justo processo inicia, segundo o TEDH, por separar nitidamente as funções de investigar e julgar e segue garantindo um elenco de direitos processuais mínimos exigíveis (ARMENTA DEU, 2012, p.277).

Ademais do entendimento do TEDH, se faz necessário, em face da posição do Brasil, averiguar o justo processo nas Américas.

\section{SITUAÇÃO NA CONVENCIONALIDADE AMERICANA}

No âmbito regional latino-americano, o direito ao justo processo pode ser compreendido como o direito ao devido processo legal de acordo com os requisitos mínimos previstos nos artigos $8^{\circ}$ e 25 da CADH. ${ }^{4}$ Nesse sentido, o direito ao justo processo está constitucionalizado no Brasil, seja em razão do artigo 5ำ, LIV, da Constituição, seja em razão do artigo 5ำ, § $2^{2}$ da CF - bloco de constitucionalidade. As garantias mínimas previstas 
nos artigos 8o e 25 da CADH, atuando harmônica e sistematicamente, são estruturantes do justo processo. Se uma dessas garantias não for respeitada e assegurada, o sistema se desorganiza, se desestrutura, e o processo não pode ser considerado como assecuratório das garantias fundamentais. Caso isso ocorra, a decisão que dele emanar recebe a mesma pecha. A realização do justo processo é condição de possibilidade à prestação da tutela judicial efetiva e da própria justiça.

Uma característica essencial do justo processo é que, embora tenha um perfil mínimo definido por critérios dogmáticos, somente pode ser reconhecido no caso concreto, mediante compreensão e conhecimento de toda a sua problemática factual e jurídica. Isso significa que as garantias se estabelecem na perspectiva da efetividade; devem possuir a entidade de proteção do bem em questão na "vida real" e não apenas no plano teórico e abstrato. 0 Estado não pode se proteger na abstração da regra, se, na prática vivenciada, ela for incapaz de proteger o direito humano (processual) ameaçado ou violado. As Cortes Interamericana e Europeia de Direitos Humanos não adotam o método clássico de subsunção do positivismo jurídico - da premissa menor à premissa maior, o que fazem é interpretar as normas convencionais, tendo a proteção da pessoa humana como fundamento e a máxima eficácia e efetividade dos direitos humanos como finalidade. Esse critério de interpretação é chamado, na jurisprudência internacional dos direitos humanos, de effet utile. Este é o termo adotado na jurisprudência do TEDH referente ao art. 13 do CEDH e seguido pela Corte IDH, para o princípio da efetividade, o que é peculiar aos direitos humanos e exige que os compromissos assumidos sejam interpretados no sentido que melhor protege a pessoa (AKANDJI-KOMBE, 2007). Esse parâmetro interpretativo adotado pela Corte IDH e pelo TEDH se materializa em uma "reação do intérprete ante o caso concreto" ${ }^{5}$ em uma perspectiva contrária à estandardização do direito e favorável ao salvamento da pessoa humana da arbitrariedade que pode advir da pura abstração da regra.

O Caso Kinský vs. The Czech Republic ilustra o que se está a dizer Nessa demanda, o TEDH (COUNCIL OF EUROPE, 2012) decidiu que havia sido violada a garantia da igualdade entre as partes no processo civil porque, paralelamente a este, o Estado, que era réu na ação cível, promoveu 
investigação criminal sigilosa contra o autor e seu advogado, obtendo diversas informações que o colocavam (o Estado) em grande vantagem em relação a outra parte, inclusive proveniente de interceptações telefônicas. Note-se que o TEDH avaliou toda a situação envolvendo as partes em ambos os processos para verificar que, naquele caso sub judice, havia sido violada a garantia da igualdade processual, e, consequentemente, o justo processo. Para o Estado livrar-se da responsabilidade internacional deveria demonstrar que o fato de ter existido o inquérito policial não favoreceu uma das partes em detrimento da outra, não sendo suficiente, por exemplo, alegar a regra abstrata da independência das instâncias. Dizendo de outro modo, os tribunais de direitos humanos não admitem que o juiz racionalize teórica e abstratamente o argumento para negar a existência de uma violação real no "mundo da vida" ou para negar algum direito humano internacionalmente consagrado. Deve ser observado o effet utile dos direitos humanos.

Um exemplo desse modo de compreender os direitos processuais e fundamentar a decisão pode ser encontrado no que diz respeito às prisões cautelares e à garantia do estado de inocência (GIACOMOLLI, 2013). É sabido que a decretação de prisão preventiva é regra antecipatória na praxis forense brasileira. Tais ordens são concedidas supostamente sem violação do estado de inocência porque, segundo o argumento corrente, tratam-se apenas de prisões processuais. Caso a pessoa passe anos detida preventivamente, e ao final do processo restar absolvida, a jurisprudência nacional não lhe garante justa indenização conforme previsto na parte final do artigo 5ํ, LXXV, da Constituição Federal, sob o argumento de tratar-se apenas de prisão instrumental. Trata-se de uma visão calcada na abstração das regras sobre a instrumentalidade desse tipo de prisão, mas sem qualquer compromisso com a dignidade da pessoa humana que, na realidade, fica privada de sua liberdade, injustamente. A prisão não é "de faz de conta", ela é real, acontece na vida de uma pessoa e isso não fica sem proteção dos tribunais internacionais.

A Corte IDH decidiu, no Caso Tibi vs. Equador (2004) ${ }^{6}$, que a prisão preventiva do suspeito, por vinte e oito meses, transformou-se de cautelar, em punitiva, já que a finalidade instrumental - para garantir o regular andamento do processo - não justifica todo esse tempo de privação de 
liberdade. Para a Corte IDH a prisão preventiva só é admissível em casos excepcionais e se absolutamente necessária, nos limites impostos pela lei. Assim, uma prisão por vinte e oito meses não se presta apenas para garantir o bom andamento do processo, mas para antecipar a pena - finalidade punitiva- o que somente é admissível após condenação em respeito ao estado de inocência - artigo 8.2 da CADH. A Corte IDH entendeu que o estado de inocência, como regra de tratamento, exige que o acusado seja tratado como inocente durante todo o processo e a manutenção da prisão do sujeito por vinte e oito meses não condiz com o tratamento devido pelo Estado a um inocente, em hipótese alguma. ${ }^{7}$

No Caso Cantoral Benavides vs. Peru, a Corte IDH (2000) declarou violada a garantia do estado de inocência, porque o suspeito foi exposto diante dos veículos de comunicação social, com uniforme de presidiário. O suspeito, segundo a Corte IDH, deveria ter sido tratado, tanto no processo, quanto perante a opinião pública como inocente até que sobreviesse sentença condenatória definitiva. Ao ser exposto com aparência de condenado, teve violada a referida garantia. Para a Corte, o estado de inocência é fundamento de todas as demais garantias judiciais, de modo que o desrespeito a esta atinge todas as demais, e o processo como um todo. A exposição pública do acusado como se culpado fosse antes da condenação definitiva importou na responsabilização internacional do Estado por violação do direito humano (processual) de ser tratado como inocente. Observa-se que, como afirmado anteriormente, a Corte analisa o problema concreto, o quanto a ação estatal impactou na vida da pessoa. A Corte não admitiu, no Caso Tibi vs. Equador, o argumento de que a prisão teria natureza cautelar como muito faz a jurisprudência brasileira para prisões até por tempo bem superior. É nesse sentido que se afirma que as garantias processuais somente podem ser verificadas no caso concreto, já que não existe justo ou injusto processo no mundo das meras abstrações. Ele se dá na realidade da vida, sem admitir alibis normativos ou argumentativos que, no caso concreto, restam vazios de sentido, que fazem com que o processo penal deixe de cumprir sua finalidade que é a proteção do indivíduo contra a arbitrariedade do Estado.

No Caso Chocrón Chocrón vs. Venezuela , a Corte IDH (2011) ao analisar o artigo 25 da $\mathrm{CADH}$, que trata do direito de acesso à justiça, 
afirmou que não basta que o Estado preveja medidas de proteção judicial em lei; é preciso que ele viabilize de fato, efetiva e concretamente, o acesso a medidas úteis por todas as pessoas que estiverem sob sua jurisdição para que possam reclamar contra atos violadores de seus direitos fundamentais. ${ }^{8}$ Dita atividade supõe que, ademais da existência formal dos recursos, estes produzam resultados ou respostas às violações dos direitos contemplados na Convenção, na Constituição ou nas leis ${ }^{9}$. Nesse sentido, não podem ser considerados efetivos aqueles recursos que, pelas condições gerais do país ou, inclusive, pelas circunstâncias particulares de um determinado caso, resultem ilusórios. Isso pode ocorrer, por exemplo, quando sua inutilidade tenha sido demonstrada na prática, por falta dos meios para executar suas decisões ou por qualquer outra situação que configure um quadro de denegação de justiça ${ }^{10}$ (Corte IDH, 2001, 2006). Assim, o processo deve tender à materialização da proteção do direito reconhecido no pronunciamento judicial mediante a aplicação idônea do dito pronunciamento (Corte IDH, 2013) ${ }^{11}$.

Esse critério hermenêutico é consentâneo à Segunda Guerra Mundial devido à experiência do Terceiro Reich, na Alemanha, onde atos de Estado se transformaram em "crimes legais". Os riscos do distanciamento absoluto do caso concreto pelos agentes estatais, fundamentados apenas na norma geral e abstrata, restaram evidenciados no exemplo extremo do regime nazista percebidos e denunciados por Hannah Arendt (1999). A Corte destacou que devem ser observadas todas as garantias previstas no artigo 8을 da CADH: "devem ser respeitadas todas as formalidades que 'sirvam para proteger, assegurar ou fazer valer a titularidade ou o exercício de um direito', isto é, "as condições que devem ser cumpridas para assegurar a adequada defesa daqueles, cujos direitos e obrigações estão sob apreciação judicial". ${ }^{12}$ Portanto, a forma se reveste de importante função garantista.

Destaca-se que o Tribunal Interamericano já se manifestou, inúmeras vezes, na mesma linha do TEDH, que, embora o artigo 8을 da CADH seja intitulado "Garantias Judiciais", sua aplicação se estende a todos os tipos de processo, não se limitando aos judiciais em sentido estrito. Tratam-se dos requisitos que devem ser observados em todas as instâncias processuais e em todas as esferas, para que "as pessoas possam se defender 
adequadamente ante qualquer tipo de ato emanado do Estado que possa afetar seus direitos". ${ }^{13}$ Nesse sentido, as garantias processuais do artigo 8o da CADH devem ser aplicadas em qualquer processo sancionatório ou que restrinja, de algum modo, o exercício de direitos fundamentais e não apenas ao processo penal formal tal qual previsto no Código de Processo Penal. Assim, o artigo 8o da CADH impõe regras também aos processos administrativos sancionadores. 0 reconhecimento do direito ao justo processo como direito humano implica aceitação de que a violação de garantias processuais consiste, por si, em ilícito internacional punível. Assim, o ilícito internacional se materializa mediante atos dos juízes na condução do processo interno, independente de qualquer afronta à legislação material doméstica.

Quando o direito humano, supostamente violado, referir-se às garantias processuais, a Corte IDH analisa o processo que tramitou no Estado acusado, tanto do ponto de vista da legislação geral e abstrata aplicável, quanto do ocorrido no processo em análise. Os "fatos" da ação internacional são as medidas adotadas no processo interno. No Caso Palamara Iribarne vs. Chile, a Corte IDH $(2005,2010)$ assentou que "o esclarecimento de o Estado ter ou não violado suas obrigações internacionais em virtude das atuações de seus órgãos judiciais pode legar a que o Tribunal deva examinar os respectivos processos internos". ${ }^{14}$ Na verdade, o juiz regional julga as decisões (ou omissões quanto ao dever de decidir) do juiz nacional em relação às exigências dos tratados internacionais de direitos humanos, fenômeno que Jânia Saldanha 2010a), adotando expressão de Anne-Marie Slaugther, denominou de judges juding judges. ${ }^{15}$

\section{DIÁLOGOS JURISDICIONAIS NECESSÁRIOS ENTRE AS CORTES}

A dicotomia verticalidade e horizontalidade, normatividade constitucional e infraconstitucional, coactividade e zonas de consenso, no âmbito jurídico, em razão da nova configuração internacional e da universalização dos direitos humanos há de ser perpassada por novas perspectivas de comunicação normativa e jurisdicional. A adequação das 
regras do processo penal, portanto, ultrapassa a mera adequação constitucional e adere à normatividade internacional, supraconstitucional, em perspectiva evolutiva das necessidades e possibilidades de realização e, sobretudo, de interdependência, em uma amplitude relacional circular, superadora dos limites da verticalidade. Em suma, na realização do justo processo na perspectiva de um direito inserido na proteção internacional dos direitos humanos.

Os Estados-Membros não são feudos e nem se constituem em planetas a gravitar em uma órbita incomunicável e isolada, mas pertencem a um cosmos articulado, interdependente, temporal e dinâmico. Há várias normatividades e dirigismos (ordinário, constitucional, convencional regional, convencional universal, v.g.), acrescendo-se, fora do plano criminal, a diversidade de normatividades privadas (autoregulações), cuja juridicização antecede ou é concomitante ao fato. Perpassam a normatividade convencional, constitucional e ordinária, a subjacência fática, em determinado tempo e lugar, moldadas pelos sujeitos. 0 resultado do processar passa por todas essas filtragens, mas sempre será uma obra humana; portanto, imperfeita e impura. A diminuição das impurezas, segundo Canotilho (2008, p. 209), depende da compreensão das normatividades pelos sujeitos processuais, na medida em que uma constituição transformadora pressupõe um sujeito transformador. A jurisprudência das cortes internacionais de direitos humanos propicia, segundo Feldens (2008, p. 100), um "lastro de interconstitucionalidade em sede de direitos fundamentais que progressivamente vai se incorporando aos programas constitucionais de cada país, dotando de maior densidade as normas e os princípios de direitos fundamentais".

Os direitos humanos não se constituem em meras declarações decorativas, em simples exortações programáticas de retórica jurídica e nem em formulismo político ocasional e oportunista, mas oferecem os pilares ao processo penal, motivo por que possuem aplicação imediata, embora, em certas situações necessitem da densificação ordinária. No mesmo cosmos da identidade do processo penal, oferecida pela normatividade constitucional estruturante, gravitam a evolução dos fatos, novas situações e realidades, novos problemas e entendimentos interpretativos, sem suma, a dinamicidade complexa de todas as dimensões da vida, a dar 
identidade constitucional e convencional aos problemas processuais. Nessa dinâmica, preserva-se o conteúdo material dos direitos fundamentais. Nessa perspectiva, a hermenêutica processual penal há de observar essas novas exigências globais, abandonar a superficialidade e secura das leis ordinárias (CPP brasileiro de 1941, ainda em vigor), evoluir da outorga de maior importância à legislação ordinária, passando pela Constituição Federal e adequando-se aos diplomas internacionais, num plano circular e complexo, muito além das coordenadas vertical e horizontal, fato-lei. Essa abertura, inclusive cultural (Haberle) permite a superação de concepções clássicas de decisionismo, estatismo, formalismo e positivismo.

A ordem jurídica contemporânea clama pelo "diálogo das fontes", pelo inter-relacionamento dialógico, na perspectiva da simbiose e não da exclusão, com um diálogo que permita a comunicação entre os sujeitos, as instituições além-fronteiras, de forma aberta e democrática, rejeitando-se os totalitarismos e imperialismos dominantes e de verdade única. Nessa perspectiva se inclui o "diálogo das fontes". Evolui-se, paulatinamente, da restrição da incidência da normatividade internacional às relações entre Estados - domestic affair - à necessidade de efetivação dos direitos fundamentais e humanos na perspectiva da cidadania - international concern (GOMES; MAZZUOLI, 2012, p. 290). A abertura às Cortes e às fontes internacionais propicia o diálogo normativo e jurisdicional, a incorporação de novos paradigmas e perspectivas de desenvolvimento do justo processo. Perceptível e factível a dinâmica dialogada entre as ordens normativas interna, regional e internacional, pois "existe uma intrínseca inter-relação entre a análise do direito internacional e do direito interno", como assentou a Corte IDH no Caso Cabrera García e Montiel Flores vs. México (2010).

0 transconstitucionalismo permite maior proteção interna e internacional dos direitos humanos, da própria normatividade ordinária e constitucional, sempre que aderente à ordem internacional. Por isso, além da ratificação dos diplomas internacionais, adquirem relevância as decisões das Cortes Internacionais, tanto dos casos envolvendo o Brasil quanto as que atingem, especificamente, outros países. Ademais da funcionalidade contenciosa da Corte IDH, emerge em elevado grau de importância a denominada "competência consultiva" (art. 64 da CADH 
e OC 01/82), a qual permite "interpretar normas jurídicas internacionais, fixando o seu alcance e conteúdo, mesmo na ausência de casos contenciosos". (RAMOS, 2001, p. 341.) Isso, independentemente do reconhecimento da jurisdição da Corte, mediante provocação da Comissão Interamericana de Direitos Humanos (CIDH), dos Estados que ratificaram a CADH e dos Estados-membros da Organização dos Estados Americanos (OEA), sempre que referentes ao sistema americano. Esses pareceres consultivos possuem dupla funcionalidade: hermenêutica e de controle da convencionalidade da legislação interna do Estado-membro. Embora se possa criticar a ausência de força vinculante e o exercício indireto da jurisdição através das opiniões consultivas (OC), estas integram o bloco de interjurisdicionalidade e se constituem em fontes hermenêuticas aos cases internos, na construção de um processo penal dos direitos humanos, evitando a responsabilização internacional do Brasil (v. OC 14/94 acerca da legitimidade da Corte IDH para responsabilizar internacionalmente o Estado por violação da Convenção). Na OC 15/97 a Corte assentou que a função consultiva se destina à interpretação da CADH e dos tratados referentes à proteção dos direitos humanos nos Estados americanos, podendo ser solicitada por todos os Estados membros da OEA, cujos efeitos jurídicos são inderrogáveis, apesar de não possuírem efeito vinculante, como ocorre com sua função contenciosa. Na OC 18/03, a Corte assentou destinar-se sua funcionalidade consultiva a extrair o sentido, o propósito e a razão das normas internacionais sobre direitos humanos, sem exame das questões de fato (item 63).

A competência da Corte (art. 64.1 da CADH) para emitir pareceres foi objeto da OC 10/89, após provocação da República da Colômbia. Desse parecer se infere a interatividade hermenêutica entre diversos diplomas internacionais: Carta Americana, Carta da OEA, CADH e outros diplomas referentes aos direitos humanos, no âmbito dos Estados Americanos. 0 Min. Gilmar Mendes, no RE 511.961 de uma ação civil pública, ao decidir acerca da obrigatoriedade do diploma de jornalismo ao exercício da referida profissão, previsto no Decreto-Lei 972/69, invocou a OC 5/85 da Corte IDH, a qual afasta tal obrigatoriedade (arts. 5ํ, IX, XIII e 220 da CF e art. 13 da $\mathrm{CADH}$ ). Essa nova ordem internacional, forjada após a Segunda Guerra Mundial, há de funcionar como uma verdadeira e suas 
decisões, apesar das resistências encontradas, servir como norte à interpretação dos casos penais internos. São os atributos de ser humano que justificam a proteção internacional e não a circunstância de pertencer a determinado Estado (preâmbulo da CADH). É uma das formas de evitar a violação aos direitos humanos. Os diplomas internacionais, em face da qualificação supra estatal, limitam os poderes dos Estados, tanto no plano interno quanto externo, modificando os conceitos clássicos de soberania, interferindo no mundo jurídico, na medida das vinculações do ius cogens (FERRAJOLI, 2002, p. 40). A suspensão de garantias contidas na CADH só se justifica nas situações expressamente enunciadas no art. 27 e, mesmo assim, de forma temporária. Ademais, a própria CADH, em seu art. 29 veda qualquer hermenêutica que exclua ou limite os direitos e as liberdades além da convencionalidade ou que excluam direitos e garantias inerentes ao ser humano, ou decorrentes da forma democrática e representativa de governo.

A defesa dos direitos humanos é um dos mecanismos para reduzir os danos provocados pela globalização e para dar sustentação ao projeto ecológico de sustentação da vida planetária. A globalização vem deixando suas marcas no processo penal, com os perigos das práticas do market sistem da plea bargaining. 0 fundamento jurídico da proteção dos direitos humanos se infere dos próprios ordenamentos jurídicos dos Estados, em suas leis fundamentais e, no caso brasileiro, na Constituição Federal, mormente quando integram à ordem jurídica interna os diplomas internacionais. Destarte, o indivíduo atinge a condição de sujeito de direito internacional, por sua condição de pessoa humana e não somente por integrar um ente político. Na compreensão da interação das diversas normatividades (jurídicas, objetivas e subjetivas), há necessidade de ser mantida uma conformidade ética, humanitária e normativa do processo penal. Nas especificidades brasileiras, há que ser considerada, além da formatação constitucional, a formatação autoreferencial social, complexa e plural, a necessidade de compreensão e afirmação do juiz como garante da CF na concretização normativa. As normatividades situam-se no complexo organizacional social em determinado espaço e tempo.

Na contemporaneidade, avolumam-se a influência dos sujeitos corporativos não-antropológicos, multifuncionais (política, economia, 
finanças, mercado, v.g.), internacionais, regionais e locais, com uma racionalidade própria e discurso emergente (CANOTILHO, 2008, p. 2017). A compreensão e proteção supranacional das garantias, dos direitos fundamentais, com preservação da dignidade dos seres humanos é um desafio que encontra eco na dinamicidade do processo penal. A governança contemporânea do processo penal insere-se na compreensão e consideração dos dilemas, paradoxos e teoremas, engendrados na pluralidade e complexidade sociais e produzidos pelo confronto das normatividades, realizadas pelos sujeitos.

O conteúdo do PIDCP, da CADH, da doutrina e jurisprudência de suas Cortes constituem a referencialidade internacional, a qual se submete a centralidade constitucional brasileira. As regras ordinárias do processo penal, por sua vez, encontram validade e eficácia quando inseridas nessa realidade convencional e constitucional. Essa é uma realidade normativa comunicante, conectada, interligada e viva; contudo, se faz mister articulá-la funcionalmente, para que seja compreendida, validada e aplicada pelos sujeitos (argumentação, discurso, prática), no caso concreto (realidade da vida). A abertura dialógica ultrapassa o puro normativismo, mesmo que supranacional, para alcançar a abertura ou comunicação jurisprudencial, o "Diálogo das Cortes” ou diálogo da jurisprudência, das decisões jurisdicionais dos Tribunais Internacionais e dos demais países. Essa nova realidade interfere nas fontes e na hermenêutica jurídica, de modo a engendrar um nível superior de jurisdição, a interjurisdicionalidade. A governança se legitima quando preserva a sua base humanitária, de desenvolvimento do ser humano. Isso se atinge, na esfera do processo penal, com a preservação dos direitos fundamentais, dos princípios democráticos, na perspectiva do justo processo. Há que se avançar do nível de normatividade ao nível de garantia da previsibilidade normativa, ao grau de efetividade dos direitos fundamentais, no qual assume relevante função a jurisdição nacional e internacional.

As decisões da Corte IDH possuem eficácia de coisa julgada formal e material (res judicata), de modo que seus efeitos não se limitam às partes (aspecto subjetivo), mas irradiam um efeito hermenêutico especial a todos os aderentes ao sistema interamericano, com eficácia erga omnes e standard interpretativo da convencionalidade e dos ordenamentos 
internos dos Estados-membros. Os efeitos não se limitam à adaptação da legislação interna, mas atingem a Law in action, como verdadeiro standard interpretativo e de proteção dos direitos humanos. ${ }^{16}$ Além da superação do monólogo interno, em todas as dimensões e perspectivas, normativas, doutrinárias e jurisprudenciais, a complexidade local e a qualidade dos cases exige tensionamento do contexto interno, diálogo de todas as fontes, inclusive entre os Tribunais de cada país, entre Tribunais de diversos países e destes com os Tribunais Internacionais (comunicação interjurisdicional). Isso permitiria uma abertura às dimensões supraestatais, o desenvolvimento e a afirmação dos direitos humanos e fundamentais.

$\mathrm{Na}$ exigência de proteção dos diretos humanos no século XXI, a perspectiva é de que as decisões das Cortes internas, da jurisprudência nacional, necessitam ser alimentadas por uma cross-fertilization "que permite o aprendizado mútuo entre diferentes sistemas jurisdicionais" (SALDANHA, 2009, p. 123), sobretudo pelas decisões das Cortes Internacionais de Direitos Humanos. Anne-Marie Slaughter fala em rede judicial (judicial network) para explicar essas relações entre cortes judiciais de diferentes países entre si, assim como as relações dos tribunais nacionais, em especial, os constitucionais, com as cortes internacionais de direitos humanos. Essa rede judicial funciona por meio de troca de informação e de fertilização recíproca (cross-fertilization) (SLAUGHTER, 2004, p. 70).

A referência a decisões de tribunais estrangeiros ou supranacionais não busca parâmetros em um sistema de direito natural, mas, sim, almeja alcançar um meio de resolver os casos concretos da melhor forma possível (GARAPON; ALLARD, 2006, p. 83). É possível e factível internalizar a norma interpretada partindo da autoridade argumentativa da decisão e não no argumento da autoridade. "A autoridade advém, atualmente, de um comércio transfronteiriço entre juízes iguais. Estes optam pela horizontalidade do intercâmbio em detrimento da verticalidade legiscêntrica ou da anterioridade do precedente" (GARAPON; ALLARD, 2006, p. 72) ${ }^{17}$. 


\section{SUPERAÇÃO DO MONÓLOGO JURISDICIONAL BRASILEI- RO E PERSPECTIVA DO DIÁLOGO ENTRE CORTES}

Embora a Corte IDH precise avaliar a validade dos atos processuais praticados pelos juízes nacionais frente aos dispositivos da CADH sempre que estiver a julgar acerca da violação do direito ao justo processo, ela não se pronuncia em grau recursal, suas decisões não possuem natureza revisional da decisão doméstica. A Corte IDH não consiste em mais uma instância de julgamento do caso já apreciado pela jurisdição nacional.

O Tribunal Interamericano limita-se a verificar se o Estado respeitou, fidedignamente, as regras do artigo $8^{\circ}$ da Convenção. A Corte IDH não valora novamente a prova produzida no âmbito interno, não decide se o acusado, em processo penal, é culpado ou inocente, ela analisa é se os direitos humanos processuais foram respeitados, como, por exemplo, se os juízes nacionais eram competentes e se gozavam de imparcialidade e independência; se foram respeitados os direitos de defesa; se foi concedido ao acusado tempo e condições adequados para elaborar sua defesa; se lhe foi possível contraditar os argumentos e provas apresentados contra si; se o processo tramitou em prazo razoável; se o acusado foi tratado como inocente durante do o processo; se foram respeitados os princípios da publicidade e da igualdade entre as partes; se o estado respeitou o direito do suspeito de não declarar contra si mesmo; se lhe foi ofertado advogado pelo Estado na hipótese de ele não poder arcar com as custas da sua defesa técnica; se eventual confissão não foi obtida mediante coação; se o estado viabilizou o pleno exercício do direito a um recurso rápido e efetivo; e assim por diante.

O sistema interamericano de direitos humanos não dispõe de meios para garantir a executividade direta das decisões da Corte IDH, sem intervenção do Conselho da OEA, que é um órgão político. As decisões emanadas do Conselho da OEA, por não serem jurisdicionais, não são dotadas de imperatividade, mas isso não significa que sejam ineficazes ou que não desempenhem função de autoridade pública. Segundo Bogdandy e Venzke (2014), quando um tribunal internacional emite uma sentença, ele atua também como autoridade pública, porque conforma relações sociais. Essa ideia de autoridade pública deve superar a no- 
ção de coerção e seguir na linha da legalidade e da legitimidade. 0 que ocorre com o acusado individualmente em um Estado quando este viola as garantias processuais daquele protegidas pelos tratados de direitos humanos vai depender do sistema de controle de constitucionalidade deste mesmo Estado (SALDANHA, 2010a, p. 136) no qual se inserem todos os direitos e garantias do bloco de constitucionalidade, o que, no Brasil, esgota-se no STF.

Assim, sempre que ocorrer a violação do direito ao justo processo, o indivíduo lesado pode levar sua demanda até a máxima corte do país a fim de ver seu caso revisado. Nessa hipótese, deve o STF alinhar sua interpretação das normas constitucionais e convencionais à hermenêutica da Corte IDH, sobretudo no que toca ao conteúdo e âmbito de alcance das garantias processuais discutidas, se a norma nacional não for mais benéfica ao acusado. Cabe ao STF exercer o controle final de convencionalidade e não apenas com base no "texto bruto" da CADH, mas, sobretudo, voltado ao conteúdo que provém da norma interpretada pela Corte IDH (res interpretata), ${ }^{18}$ pois o texto abstrato e universalizante contido nas leis são apenas "textos" e não normas jurídicas, porque estas já nascem interpretadas. Como afirma Lênio Streck (2000, p. 123), "a Constituição é, finalmente, o resultado de sua interpretação, uma vez que uma coisa só é (algo, uma coisa) na medida em que é interpretada (porquê compreendida "como" algo)." Assim são as normas da CADH e demais pactos internacionais de direitos humanos, elas somente se tornam normas quando interpretadas pela Corte IDH, órgão do sistema interamericano competente para sua interpretação. Antes da interpretação, a CADH possui apenas um texto, ainda carente de norma. Esta emana da problematicidade do caso concreto. Por isso, o STF deve fomentar e vivenciar diálogos jurisprudenciais com os tribunais internacionais de direitos humanos, principalmente com a Corte IDH. Esses diálogos entre cortes têm grande potencial para sedimentar e conferir densidade às garantias previstas na própria Constituição e não para, necessariamente, só internalizar garantias convencionais, sobretudo quando essas mesmas garantias processuais estiverem previstas tanto em pacto internacional, quanto na Constituição. 
Os diálogos entre as cortes nacionais e internacionais permitem concretizar os efeitos (indiretos) das decisões da Corte IDH a todos os estados jurisdicionados, ainda que não tenham sido parte no caso contencioso, porque, a semelhança das decisões do TEDH, elas enunciam "erga omnes a interpretação das disposições da Convenção” (MANES, 2011, p. 93) os quais todos os Estados tendem a seguir para evitar que incorram em iguais violações. Nessa mesma linha, Armenta Deu (2012, p. 237) defende que, nas Américas restou consagrada a vinculação normativa da legislação interna às decisões da Corte IDH na sua função hermenêutica, impondo a vinculação dos estados para além do caso concreto. Assim, a jurisprudência das cortes internacionais surge como importante fonte do Direito. Nesse sentido, ao analisar qualquer alegação de violação da CADH em grau recursal, ou por ação de sua competência originária, o STF deve proporcionar a incidência das decisões da Corte IDH aos casos litigiosos nacionais pela via da aplicação da norma interpretada - res interpretata, ou seja, conforme conteúdo, alcance e âmbito de proteção reconhecidos pelo Tribunal interamericano, mesmo que o Brasil não tenha sido parte na contenda. A Corte Suprema de Justiça da Nação Argentina desenvolveu doutrina segundo a qual a Argentina deve observar a hermenêutica da Corte IDH, mesmo que não seja parte no caso concreto, ainda que existam consequências distintas para os casos contenciosos (ARMENTA DEU, 2012, p. 272).

Invoca-se, a título de exemplo, a interpretação dada pela Corte IDH ao artigo 8.2 da CADH que garante que o acusado mantenha o estado de inocência até que seja provada sua culpa como previsto em lei. Com base na res interpretata, o STF precisa conter a banalização do instituto processual da prisão preventiva, conforme a praxe forense das instâncias inferiores. A prisão preventiva somente pode ser aplicada quando absolutamente necessária e pelo prazo suficiente para salvaguarda do processo, jamais podendo prolongar-se por tanto tempo a ponto de alterar seu "DNA" de cautelar para punitiva, em antecipação inconvencional e inconstitucional da pena. Ainda para proteção do estado de inocência - que é fundamento de todas as demais garantias que estruturam o justo processo - o STF há de dar respostas úteis - no sentido de efetiva no caso concreto - para proteger os acusados da constante exposição midiática a 
que são submetidos quando estão sob custódia do Estado - o que é fato notório e corriqueiro no Brasil - em contrariedade à norma convencional conforme interpretada pela Corte IDH. ${ }^{19}$

Nessa mesma linha, o STF não pode mais ignorar a necessidade de interpretação conforme à CADH que deve ser dada ao Código de Processo Penal, como, por exemplo, ao artigo 156, na medida em que tal dispositivo legal jamais pode ser interpretado de forma a atribuir ao acusado o ônus de provar sua inocência. Isso implica que deve ser reavaliada a jurisprudência nacional quanto ao suposto ônus do acusado provar as excludentes de ilicitude e culpabilidade e mesmo algum álibi. ${ }^{20}$ Essa interpretação se afasta da convencionalidade, conforme sentenças da Corte IDH nos casos Casos Herrera Ulloa vs. Costa Rica (2004), López Mendoza Vs. Venezuela (2011) e Ricardo Canese Vs. Paraguai (2004).

Independente disso, o mais importante e salutar é que o STF reveja sua jurisprudência consolidada de que a violação do artigo $5^{\circ}$, LIV, da CF brasileira somente se dá de forma reflexa, ou seja, mediante violação direta apenas de norma infraconstitucional, o que afastaria o controle do pretório excelso pela via do recurso extraordinário. ${ }^{21}$ O STF precisa conhecer desses recursos e julgar o mérito da alegada violação da garantia processual ao devido processo legal, porque consiste em arguição de violação do justo processo, cuja afronta é sempre direta e frontal à CADH no sentido que lhe dá a Corte IDH, logo ao bloco de constitucionalidade. O STF precisa, alimentando-se da jurisprudência da Corte IDH, admitir recursos que aleguem violação ao devido processo legal, nutrindo-se da doutrina do justo processo que lhe permitirá conferir densidade à norma constitucional do artigo 5o, LIV, e salvaguardar os direitos humanos processuais violados nesses casos. Não conhecer do recurso extraordinário fundado em alegação de violação do justo processo, sob o fundamento de que não há violação direta à Constituição resulta, de fato, em negar prestação jurisdicional para garantir o direito ao justo processo no sentido que lhe dá à Corte IDH. Isso, porque como já assentado pelo Tribunal regional interamericano, o fato de existir previsão no ordenamento interno quanto à possibilidade de recorrer, não é suficiente para que a norma da CADH seja cumprida; é preciso que o recurso seja efetivo para proteger toda pessoa da violação de direitos humanos. Negar acesso ao 
recurso extraordinário para discutir o conteúdo do justo processo como direito humano, significa tornar as regras da CADH inócuas e ineficazes, o que vai de encontro ao entendimento amadurecido dos tribunais internacionais sobre efetividade perante o caso concreto.

A tese vigente hoje de que as ofensas ao devido processo legal são sempre diretas às leis processuais e somente pela via reflexa violam à Constituição significa, na law in action, deixar o direito ao justo processo nacional vazio de sentido, porque as maiores violações provem do próprio texto legal ou da interpretação que lhe é dada pelos tribunais competentes como, tradicionalmente, se dá, apenas para ficar nesse exemplo, com a distribuição do ônus da prova resultante da inconvencional interpretação do artigo 156 do CPP pelas demais instâncias. É o STF quem deve delinear o conteúdo mínimo do artigo 5ㅇ, LIV, da Constituição Federal, independente do que diz a legislação infraconstitucional ou adotar a interpretação já dada pela Corte IDH, se esta for mais favorável ao acusado. Negar essa análise significa, na prática, negar a concretização dos direitos humanos previstos na $\mathrm{CADH}$, podendo o lesado buscar o tribunal internacional que, diante da incapacidade nacional, poderá acudi-lo em razão de sua competência subsidiaria.

Assim, pode acontecer de ser o próprio STF o órgão jurisdicional responsável pela violação - primária ou derivada - dos direitos e garantias processuais protegidos nos tratados internacionais de direitos humanos. Nesse caso, resta ao lesado promover ação perante a Corte IDH para responsabilizar o Brasil que atuará como parte em processo contencioso, cuja decisão deve cumprir com base no artigo 63 da CADH. De um modo geral, o Brasil tem cumprido as decisões da Corte IDH na parte em que determina o pagamento de indenizações. Em caso de não cumprimento, o favorecido na sentença internacional pode promover sua execução internamente nos termos do artigo 68.2 da Convenção. Não há necessidade de homologação pelo Superior Tribunal de Justiça (STJ), nos termos do artigo 105, I, CF, devendo ser executada no primeiro grau da Justiça Federal, já que é a União que responderá no âmbito interno. As sentenças da Corte IDH dispensam homologação, porque não se enquadram na classificação de sentenças estrangeiras que são aquelas proferidas em outro Estado, por sua jurisdição, para serem cumpridas no 
Brasil. As decisões de São José são sentenças internacionais proferidas em processo do qual o Brasil foi parte e emanadas de Tribunal do qual, livremente, reconheceu jurisdição.

No plano interno brasileiro, não existe regramento específico para dar cumprimento às decisões de natureza não patrimonial. ${ }^{22}$ No entanto, entende-se possível dar cumprimento a determinadas obrigações de fazer, assegurando ao prejudicado o gozo do seu direito ou liberdade violados nos termos do artigo 63 da CADH, por meio dos procedimentos já existentes na legislação processual brasileira, ainda que seja necessário fechar "gaps" como afirma Ferrajoli (2001). Esse fechamento de "gaps" pode ser feito, inclusive, pela invocação de outros tratados a fim de conferir maior densidade ao conteúdo das normas previstas na CADH. Essa incorporação do conteúdo normativo de outros tratados à CADH tem construção pretoriana no sentido da máxima expansão e efetividade dos direitos humanos. Lixinski $(2010,587)$ destaca que qualquer instrumento internacional pode ser usado para expandir o conteúdo normativo dos direitos previstos na $\mathrm{CADH}$, porque os direitos humanos são interdependentes.

O ordenamento interno dispõe de medidas processuais que permitem tornar efetivas, no todo ou em parte, as decisões contenciosas da Corte IDH contra o Brasil, seja pela via do habeas corpus, do mandado de segurança ou da revisão criminal, dependendo da medida prática que se pretende tornar efetiva e da adequação da via para acudir o direito em questão. Cada violação vai precisar de um remédio distinto.

No contexto da violação de alguma das garantias do artigo $8^{\circ}$ em que se faz necessária a adoção de mecanismo interno para dar cumprimento à decisão mandamental da Corte IDH, pode surgir o problema da (in) adequação das normas internas para dar-lhe efetividade, conforme determinado na "legalidade" da CADH, que poderia, quiçá, implicar em nova violação de direito humano processual diante da denegação de proteção judicial prevista no artigo 25 da CADH.

0 propósito do artigo 63 da CADH é que o lesado tenha seus direitos humanos restituídos. Por isso, defende-se que as decisões da Corte IDH em que o Brasil tomar parte devem ser uma causa específica de revisão criminal a ser inserida no artigo 655 do Projeto de Lei 156/2009 do 
Senado Federal, atualmente tramitando sob no 8.045/2010 na Câmara dos Deputados, que objetiva uma reforma global do Código de Processo Penal. A França dispõe de lei específica que prevê a possibilidade de revisão de uma sentença condenatória nacional em caso de decisão contra a França pelo TEDH. O pedido de revisão deve ser apresentado dentro do prazo de um ano a contar da decisão internacional (ARMENTA DEU, 2012, p.250). Assim, uma decisão vinculante de tribunal internacional de direitos humanos terá força para anular ou revisar decisão interna mesmo transitada em julgado por violação de garantias processuais. Tem-se o exemplo dos casos Bulacio v. Argentina e Espósito v. Argentina que foram acatadas e aplicadas no próprio ordenamento argentino. Ambos os casos debatiam prescrições de crimes do período ditatorial reconhecidas pela corte suprema argentina que revogou a decisão anterior com base nos artigos 1 e 2 da CADH (ARMENTA DEU, 2012, p. 250).

Defende-se que, embora uma alteração legislativa nacional seja recomendável para internalização das decisões da Corte IDH, ela não se faz necessária, porque o ordenamento jurídico brasileiro tem meios processuais para dar efetividade às decisões de cunho não patrimonial da Corte IDH quanto à violação do direito ao justo processo. 0 artigo 621, I, do CPP, por exemplo, merece interpretação ampliativa para viabilizar a restituição dos direitos violados ao lesado. Além disso, nesses casos caberia habeas corpus se ameaçada ou violada a liberdade de locomoção, ou mandado de segurança em caso negativo, já que o direito a um processo justo é direito líquido e certo e a sentença internacional esvazia a necessidade de qualquer instrução probatória. Aliás, as decisões da Corte IDH são títulos executivos. 0 ordenamento jurídico brasileiro dispõe de meios processuais para dar efetividade às decisões da Corte IDH para muito além do pagamento de indenizações e concretizar os direitos humanos. Talvez as barreiras maiores não estejam no Direito, mas no "fechamento da mentalidade dos juristas, que trabalham no processo, ao seu próprio sistema, furtando-se do exercício da denominada fertilização recíproca" (SALDANHA, 2009, p. 123). 


\section{CONSIDERAÇõES FINAIS}

A inserção do Brasil no Sistema Interamericano de Direitos Humanos, a partir da ratificação da CADH e da aceitação da jurisdição da Corte IDH, abre novas perspectivas de efetividade da tutela jurisdicional criminal. Por isso, a legislação ordinária e, inclusive a constitucional, submetem-se ao filtro da convencionalidade. Não é só, a jurisdição brasileira há de dialogar, no plano horizontal e vertical, com as decisões das Cortes internacionais, sobretudo as referentes aos Direitos Humanos. Tudo na perspectiva do estabelecimento de standard protetivo das garantias processuais penais, conformadoras do justo processo.

No âmbito regional latino-americano, o justo processo pode ser compreendido como o direito ao devido processo legal, de acordo com os requisitos mínimos previstos nos artigos $8^{\circ}$ e 25 da CADH. Especificamente no Brasil, recebe o crivo da constitucionalização no artigo 5을 LIV, da Constituição Federal, bem como em razão do artigo 5o $§ 2^{\circ}$ da $\mathrm{CF}$ - bloco de constitucionalidade. Transgredida qualquer garantia, o sistema se desestrutura, o processo não pode ser considerado como assecuratório das garantias fundamentais e a tutela jurisdicional carecerá de efetividade. A realização do justo processo é condição de possibilidade à prestação da tutela judicial efetiva e da própria justiça.

Não existe regramento específico para dar cumprimento às decisões de natureza não patrimonial, no ordenamento jurídico brasileiro. Contudo, entende-se possível dar cumprimento a determinadas obrigações de fazer, assegurando ao prejudicado o gozo do seu direito ou liberdade violados nos termos do artigo $63 \mathrm{da} \mathrm{CADH}$, por meio dos procedimentos já existentes na legislação processual brasileira, como o habeas corpus, o mandado de segurança ou a revisão criminal.

A partir de toda essa análise, tem-se que normatividade e a jurisdicionalidade domésticas não são suficientes à tutela efetiva das garantias processuais penais, ou seja, do justo processo.

A hermenêutica processual penal há de evoluir da outorga de maior importância à legislação ordinária, passando pela Constituição Federal e adequando-se aos diplomas internacionais, num plano circular e complexo, além das coordenadas fato-lei. Essa abertura, inclusive cultural é 
condição de possibilidade de superação de concepções clássicas de decisionismo, estatismo, formalismo e positivismo. A tutela judicial efetiva, na complexidade da sociedade contemporânea, clama pelo "diálogo das fontes", pelo inter-relacionamento dialógico, na perspectiva da simbiose, de aproximação, e não da exclusão, permitindo a comunicação entre os sujeitos, as instituições além-fronteiras, de forma aberta e democrática, rejeitando-se os totalitarismos e imperialismos dominantes e de verdade única. A abertura às Cortes e às fontes internacionais propicia o diálogo normativo e jurisdicional, a incorporação de novos paradigmas e perspectivas de desenvolvimento das garantias processuais penais, do justo ou devido processo penal.

\section{NOTAS}

1 V. Voto concorrente do juiz interamericano Diego Garcia-Sayán, no Caso Barbani Duarte y Otros vs. Uruguay (2011). Disponível em: <www.corteidh.or.cr>. Acesso em: 15.02.2017.

2 Ver arts. 10 e 11 do Ato Institucional no 5, de 13 de dezembro de 1968. Disponível em: <legis.senado. gov.br/legislacao/ListaNormas.action?numero=5\&tipo_norma=AIT\&data=19681213\&link=s>. Acesso em: 21.02.2017.

3 Para maiores informações ver: <http://www.mirandawarning.org/whatareyourmirandarights. html >. Acesso em: 19.02.2017 e < http://constitution.findlaw.com/amendment5/annotation09. html\#6>. Acesso em: 19.02.2017.

4 O Juiz interamericano Antônio Augusto Cançado Trindade, no caso do Massacre de Pueblo Bello Vs. Colômbia (2006), sustentou haver indissociabilidade entre os artigos 8o e 25 da Convenção como um "avanço jurisprudencial intangível" (pars. 44-52). Disponível em: <http://www.corteidh. or.cr/docs/casos/articulos/seriec_140_esp.pdf>. Acesso em: 21.02.2017.

5 A expressão é de Jânia Maria Lopes Saldanha (2010a, p. 130).

6 Caso Tibi vs. Equador (2004). Também, no Caso Suarez Rosero vs. Equador (1997), a Corte IDH assentou que a liberdade da pessoa detida não pode ser restringida "além dos limites estritamente necessários para assegurar que não impedirá o desenrolar eficiente das investigações e que não prejudicará a ação da justiça, pois a prisão preventiva é uma medida cautelar não punitiva...". No caso, Rosero havia permanecido preso preventivamente de 23.06.1992 a 29.04. 1996, tendo sido condenado na pena de dois anos de prisão, por tráfico de drogas. Disponível em: <www. corteidh.or.cr>. Acesso em: 16.02.2017.

7 V. o Caso Suárez Rosero vs. Equador. Disponível em: <www.corteidh.or.cr>. Acesso em: 16.02.2017.

8 V. também, o Caso Velásquez Rodríguez vs. Honduras; o Caso Rosendo Cantú y otra vs. México e o Caso Cabrera García y Montiel Flores vs. México. Disponível em: <www.corteidh.or.cr >. Acesso em: 16.02.2017.

9 V. Caso Tribunal Constitucional vs. Peru. Caso Reverón Trujillo vs. Venezuela; Caso Barreto Leiva vs. Venezuela. Disponível em: <www.corteidh.or.cr>. Acesso em: 16.02.2017.

10 V. também o Caso Ivcher Bronstein vs. Peru (2001); o Caso Acevedo Jaramillo y otros vs. Peru (2006) e o Caso Acevedo Buendía y otros ("Cesantes y Jubilados de la Contraloría") vs. Peru. Disponível em: <www.corteidh.or.cr>. Acesso em: 16.02.2017.

11 V. também o Caso Baena Ricardo y otros vs. Panamá (2003); o Caso Acevedo Jaramillo y otros vs. Peru; e o Caso Acevedo Buendía y otros ("Cesantes y Jubilados de la Contraloría") vs. Peru. Disponível em: <www.corteidh.or.cr>. Acesso em: 16.02.2017. 
12 V. Caso Herrera Ulloa; Caso Maritza Urrutia, e Caso Myrna Mack Chang. Disponível em: <www. corteidh.or.cr>. Acesso em: 17.02.2017.

13 V. Caso del Tribunal Constitucional vs. Peru (2001). V. também, exemplificadamente, o Caso Barbani Duarte y otros vs. Uruguay (2011), o Caso Apitz Barbera e Outros vs. Venezuela (2008), o Caso Chocrón Chocrón vs. Venezuela (2011), o Caso Vélez Loor vs. Panamá (2010), o Caso Paniagua Morales vs. Guatemala, todos disponíveis em < http://www.corteidh.or.cr/>. Disponível em: $<$ www.corteidh.or.cr>. Acesso em: 15.02.2017.

V. também as seguintes decisões do TEDH: Case of Engel and Others vs. The Netherlands (1976), Case of Öztürk vs. Germany (1984), Case of Anghel vs. Romênia (2007), Case of Sud Fondi vs. Italy (2009), Case of Sergey Zolotukhin vs. Russia (2009). Disponível em: <http://www.echr.coe.int/ Pages/home.aspx?p=home>. Acesso em: 18.02.2017.

14 V. o Caso Vélez Loor vs. Panamá (2010), o Caso de la "Masacre de Mapiripán", o Caso de la Comunidad Moiwana, o Caso de las Hermanas Serrano Cruz, o Caso Herrera Ulloa, o Caso Myrna Mack Change, o Caso Juan Humberto Sánchez, o Caso Juan Humberto Sanchez, o Caso Bámaca Velásquez, o Caso de los "Niños de la Calle" (Villagrán Morales y otros). Disponível em: <www.corteidh.or.cr>. Acesso em: 17.02.2017.

15 A referência a esse fenômeno que pode ser traduzido como "juízes julgando juízes" deve ser entendida no sentido metafórico, na medida em que não são os juízes nacionais que estão sob julgamento internacional, mas o Estado em que exercem jurisdição. Ademais, compreendendo-se o processo internacional na Corte IDH como um mecanismo para julgar fatos cometidos por autoridades estatais e não pessoas, esse fenômeno pode ser compreendido como "juízes julgando atos praticados por juízes no exercício da jurisdição".

16 V. Caso Vélez Loor vs. Panamá (2010). Disponível em: <www.corteidh.or.cr>. Acesso em: 12.02.2017.

17 Os autores denominam "comércio entre juízes" as operações judiciais que outros autores podem compreender como "diálogos ente juízes", "mundialização judicial" ou "auditório global". A opção pela expressão "comércio entre juízes" busca remetê-lo a duas faces da chamada mundialização do direito, "é simultaneamente, uma rede de trocas, intercâmbios, e uma forma de sociabilidade nascida do desejo de estabelecer relações sólidas, corteses, serenas, uma 'dependência recíproca dos homens'.

18 V. voto do juiz Eduardo Ferrer Mac-Gregor Poisot no Caso Gelman Vs. Uruguay (2013). Disponível em: $<$ http://www.corteidh.or.cr/docs/supervisiones/gelman_20_03_13.doc.>. Acesso em 15.02.2017.

19 V. Caso Cantoral Benavides vs. Peru (2000). Disponível em: <www.corteidh.or.cr>. Acesso em: 12.02.2017.

20 Por todos, ver os seguintes acórdãos do STJ: REsp 612.367/RJ, Rel. Min. Gilson Dipp, DJ 14.06.2004. REsp, 866.394/RJ, Rel. Min. Laurita Vaz, Quinta Turma, DJe 22.04.08. AgRg no REsp 871.739/ PE, Rel. Min. Arnaldo Esteves Lima, Quinta Turma, DJe 09.12.2008. AgRg no REsp 1367491/PR, Rel. Min. Jorge Mussi, Quinta Turma, DJe 02.05. 2013. Disponível em: <www.stj.jus.br>. Acesso em: 10.01.2017.

21 Apenas a título de exemplo ver os seguintes acórdãos do STF: ARE 754384 AgR, Relator(a): Min. Ricardo Lewandowski, Segunda Turma, julgado em 27.08.2013, ARE 727207 AgR, Relator(a): Min. Teori Zavascki, Segunda Turma, julgado em 27.08.2013, ARE 697757 AgR, Relator(a): Min. Rosa Weber, Primeira Turma, julgado em 27.08.2013, I 599146 AgR, Relator(a): Min. Gilmar Mendes, Segunda Turma, julgado em 27.08.2013, ARE 752933 AgR, Relator(a): Min. Cármen Lúcia, Segunda Turma, julgado em 20.08.2013. Disponível em: <www.stf.jus.br>. Acesso em 20.01.2017.

22 Ressalta-se que tramitou, no Senado Federal, o Projeto de Lei no 170/2010, o qual restou arquivado ao final da legislatura, em 26.12.2014, com base no artigo 332 do Regimento Interno. Esse projeto previa apenas a execução das obrigações de pagamento, nada referindo sobre obrigações de fazer ou não-fazer em que o Brasil restasse condenado pela Corte IDH. Disponível em: < http:// www25.senado.leg.br/web/atividade/materias/-/materia/98360>. Acesso em: 22.02.2017. 


\section{EFERÊNCIAS}

AKANDJI-KOMBE, Jean-François. Positive Obligations under European Convention on Human Rights: A guide to the implementation of the European Convention on Human Rights. Human rights handbooks, No. 7. Belgium: Council of Europe, 2007. Disponível em: < https://rm.coe.int/168007ff4d >. Acesso em: 2. Jul. 2017

ARENDT, Hannah. Eichmann em Jerusalém: um relato sobre a banalidade do mal. São Paulo: Companhia das Letras, 1999.

ARMENTA DEU, Teresa. Sistemas Procesales Penales: La justicia penal em Europa y América - Un camino de ida y vuelta? Madrid: Marcial Pons, 2012.

BOGDANDY, Armin Von; VENZKE, Ingo. In: Whose Name? A Public Law Theory of International Adjudication. Tradução de Thomas Dunlap. Oxford: Oxford University Press, 2014. [e-book].

BRASIL. PRESIDÊNCIA DA REPÚBLICA. Disponível em: <http://www2.planalto. gov.br/>. Último Acesso em: 22.02.2017.

BRASIL. SENADO FEDERAL. Disponível em: <http://www12.senado.leg.br/ hpsenado>. Último Acesso em: 22.02.2017.

BRASIL. SUPERIOR TRIBUNAL DE JUSTIÇA. Disponível em: <www.stj.jus.br>. Último acesso em 20.02.2017.

BRASIL. SUPREMO TRIBUNAL FEDERAL. Disponível em: <www.stf.jus.br>. Último Acesso em: 20.02.2017.

CANOTILHO, J.J. Gomes. "Brancosos" e Interconstitucionalidade. Coimbra: Almedina, 2008.

COUNCIL OF EUROPE. European Court of Human Rights. Annual Report 2012: Registry of the European Court of Human Rights Strasbourg, 2013. Disponível em:<http://www.echr.coe.int/Documents/Annual_report_2012_ENG.pdf >. Acesso em: 20.02.2017. 
Annual Report 2013: Registry of the European Court of Human Rights Strasbourg, 2014. Disponível em:< http://www.echr.coe.int/Documents/Annual_report_2013_ENG.pdf>. Acesso em: 20.02.2017.

Annual Report 2014: Registry of the European Court of Human Rights Strasbourg, 2015. Disponível em:< http://www.echr.coe.int/Documents/Annual_report_2014_ENG.pdf>. Acesso em: 20.02.2017.

Annual Report 2015: Registry of the European Court of Human Rights Strasbourg, 2016. Disponível em:< http://www.echr.coe.int/Documents/Annual_report_2015_ENG.pdf>. Acesso em: 20.02.2017.

Annual Report 2016: (provisional version): Registry of the European Court of Human Rights Strasbourg, 2017. Disponível em:< http://www.echr. coe.int/Documents/Annual_report_2013_ENG.pdf>. Acesso em: 20.02.2017.

FELDENS, Luciano. Direitos fundamentais e direito penal. Porto Alegre: Livraria do Advogado, 2008.

FERRAJOLI, Luigi. Fundamental Rights. International Journal for the Semiotics of Law, Holanda, n. 14, 2001, p. 1 - 33.

Soberania no mundo moderno: nascimento e crise do Estado Nacional. São Paulo: Martins Fontes, 2002.

FIND LAW. Disponível em: < http://constitution.findlaw.com/amendment5/ annotation09.html\#6>. Último Acesso em: 22.02.2017.

GARAPON, Antoine; ALLARD, Julie. Os juízes na mundialização: a nova revolução do direito. Lisboa: Instituto Piaget, 2006.

GIACOMOLLI, Nereu José. Prisão, Liberdade e as Cautelares alternativas ao Cárcere. Madrid: Marcial Pons, 2013.

GOMES, Luiz Flávio e MAZZUOLI, Valério de Oliveira. “Crimes da Ditadura Militar e o Caso Araguaia: aplicação do Direito Internacional dos Direitos Humanos pelos Juízes e Tribunais Brasileiros", em OLIVEIRA, B.Q. e SANTIAGO, N.E.A. (org.). Direito penal e século XXI: desafios e perspectivas. Florianópolis: Conceito Editorial, 2012. 
LIXINSKI, Lucas. Treaty Interpretation by the Inter-American Court of Human Rights: Expansion is matthe Service of the Unity of International Law. European Journal of International Law, v. 21, n. 3, p. 585-604, 2010.

LUZ, Denise. Direito administrativo sancionador judicializado: improbidade administrativa e devido processo - aproximações e distanciamentos do direito penal. Belo Horizonte: Juruá, 2014.

MANES, Vittorio. "As Garantias Fundamentais em Matéria Penal, entre a Constituição e Convenção Europeia de Direitos do Homem", em D’AVILA, Fábio Roberto. Direito Penal e política criminal no terceiro milênio: perspectivas e tendências. Porto Alegre: EDIPUCRS, 2011.

MIRANDA WARNING ORGANIZATION. Disponível em: <http://www.mirandawarning.org/whatareyourmirandarights.html>. Último Acesso em: 22.02.2017.

ORGANIZAÇÃO DOS ESTADOS AMERICANOS. Corte Interamericana de Direitos Humanos. Disponível em: <http://www.corteidh.or.cr/>. Último Acesso em: 21.02.2017.

RAMOS, André de Carvalho. Direitos humanos em juízo: comentários aos casos contenciosos e consultivos da Corte Interamericana de Direitos Humanos. São Paulo: Max Limonad, 2001.

SALDANHA, Jânia Maria Lopes. A paradoxal face 'hipermoderna' do processo constitucional: um olhar sobre o direito processual brasileiro. Estudios Constitucionales, Talca, ano 8, n. 2, p. 686, 2010b. Disponível em: <http://www.scielo. cl/pdf/estconst/v8n2/art20.pdf>. Acesso em: 19.02.2017.

. Bloco de constitucionalidade em matéria de garantias processuais na América Latina: Ultrapassando o perfil funcional e estrutural 'hipermoderno' de processo rumo à construção de um direito processual internacional dos direitos humanos, In: STRECK, L. L; ROCHA; L.S.; CALLEGARI; A.L. (Org.). Constituição, sistemas sociais e hermenêutica. Porto Alegre: Livraria do advogado, 2010a.

. Do funcionalismo processual da aurora das luzes às mudanças processuais estruturais e metodológicas do crepúsculo das luzes: a revolução paradigmática do sistema processual e procedimental de controle concentrado da constitucio- 
nalidade no STF. In STRECK, L.L.; MORAIS, J.L.B. (Org.). Constituição, sistemas sociais e hermenêutica. Porto Alegre: Livraria do Advogado, 2009.

SLAUGHTER, Anne-Marie. A new world order. Princeton: Princeton University Press, 2004.

STRECK, Lênio Luiz. A hermenêutica e o acontecer (Ereignen) da Constituição: A tarefa de uma nova crítica do Direito In: ROCHA, Leonel Severo.; STRECK, Lênio Luiz.; MORAES, José Luís Bolzan de. (Orgs.) Anuário do Programa de Pós-Graduação em Direito: mestrado e doutorado. São Leopoldo: Unisinos, 2000.

Recebido em: 30-4-2017

Aprovado em: 10-9-2018

\section{Denise Luz}

Doutoranda em Ciências Criminais PUC-RS, com auxílio CAPES; mestre em Ciências Criminais PUCRS; professora de Direito Penal e Direito Processual Penal na Universidade de Pernambuco - UPE. E-mail: dnluz@terra.com.br

\section{Nereu José Giacomolli}

Doutor em Estudios de Actualidad Procesal pela Universidad Complutense de Madrid; professor do Programa de Pós-Graduação stricto sensu - Mestrado e Doutorado - em Ciências Criminais da PUC-RS; professor convidado do mestrado em Ciências Policiais do Instituto Superior de Ciências Policiais e Segurança Interna de Portugal, da Universidade Autónoma de Lisboa. E-mail: nereu@giacomolli.com

Programa de Pós-Graduação em Direito da Universidade Federal do Rio Grande do Sul

Av. João Pessoa, 80, $2^{\circ}$ andar - 90.040-000 Porto Alegre - RS - BRASIL 